\title{
QUANTITATIVE ASSESSMENT OF WORKING CONDITIONS IN THE WORKPLACE
}

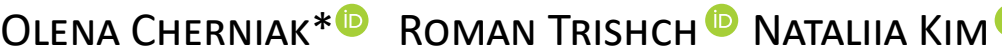 \\ SABINA RATAJCZAK
}

\begin{abstract}
A B S T R A C T
Indicators, different in terms of nature and grading scales, are used to recognise hazardous and harmful factors that affect human health. However, no single methodology is available for their assessment, and the variety of qualimetric assessment methods requires in-depth research, in part on optimality and efficiency. Therefore, this work aimed to conduct several scientific studies to obtain the results of the assessment in unified units of measurement, which would provide a generalised indicator of harmful factors at the workplace. The article proposes to use dependencies to assess indicators of harmful factors, considering the maximum, minimum, and optimal values as well as the shape parameter, the change of which produces various assessments in a dimensionless scale. A hierarchy analysis method was used to obtain reliable values with a small number of experts and determine the form parameter. These efforts resulted in the value of the overall index for harmful factors, which serves as grounds for decisions regarding further improvements in working conditions. The developed methodology was used to assess the safety of working conditions at a machine-building enterprise, and the results are presented in the article.
\end{abstract}

KEY WORDS

quantitative assessment, management, shape parameter, dependence, overall index

10.2478/emj-2020-0014
Olena Cherniak

Ukrainian Engineering Pedagogics Academy, Ukraine ORCID 0000-0001-6167-8809

Coresponding author: e-mail: olena-cherniak@ukr.net

Roman Trishch

Ukrainian Engineering Pedagogics Academy, Ukraine ORCID 0000-0003-3074-9736

Nataliia Kim

Mykolaiv National Agrarian University, Ukraine ORCID 0000-0002-1110-8522

Sabina Ratajczak

WSB University, Poland ORCID 0000-0003-4257-0805

\section{INTRODUCTION}

The quality of our life, in general, is determined by many factors, such as education, the state of healthcare, freedom of speech, and occupational safety. The national occupational safety situation is indicative of the public attitudes towards such most significant values as human life. Based on international experience, a work organisation that ignores occupational safety requirements undermines the economic efficiency of enterprises and cannot be the basis for a sustainable

Cherniak, O., Trishch, R., Kim N., \& Ratajczak, S. (2020). Quantitative assessment of working conditions in the workplace. Engineering Management in Production and Services, 12(2), 99-106. doi: 10.2478/emj-2020-0014 
development strategy. The UN concept of "sustainable human development" considers work safety as one of the basic human needs. It is, therefore, urgent to ensure occupational safety at the stages of product design, manufacture, and operation and develop technologies that are safe for the life and health of the employees. Safe working conditions demand a constant process of their assessment, analysis and continuous management.

Occupational safety management aims to develop a system of measures that provide objective information about a managed asset, aiming to develop and adopt managerial decisions required to make it safer. Effective management requires more advanced and cost-effective methods of information collection and processing.

In practice, the assessment of working conditions is reduced to the identification of work-related harmful and dangerous factors, and the establishment of the quantitative degree of work-related health risks. To accurately predict and minimise harmful and dangerous factors, it is necessary to carry out their assessments, which must be quantified. Therefore, there is a need for research and development of modern management solutions aimed at enhancing the protection of employees from harmful factors, including the improvement of methods for assessing working conditions and the search for new criteria. Thus, the article aims to develop a quantitative evaluation method for the safety of working conditions.

\section{LITERATURE REVIEW}

As is widely known, the process of work involves factors related to the environment and processes that can affect health. However, a complete exclusion of unfavourable factors from the production environment is impossible even in industries with advanced process technologies, modern equipment, high production culture and excellent medical care. For example, mechanical engineering is characterised by a large number of work-related and occupational diseases, such as sensorineural hearing loss, vibration disease, pneumoconiosis, dust bronchitis, musculoskeletal disorders and peripheral nervous systems diseases (Suuronen et al., 2007; Azizi, 2010; Bonner, 2010). Therefore, their assessment is urgent aiming to predict and prevent harmful and dangerous production factors.

In a company, the occupational protection and risk management system is a part of the overall management system, which functions to increase the level of safety at work, to reduce, prevent and eliminate exposure to hazardous factors and to manage risks associated with hazards (Holubova, 2016).

Tabor (2018) argued that the development of health and safety management systems and the tendency to integrate them with other management systems in the company create serious requirements for assessing their effectiveness. The researcher proposed to use the Gray System Theory (GST), Simos procedure at the stage of determining the weights of individual elements pertaining to the health and safety management system, as well as the method of arithmetic mean at the stages of aggregation assessment.

The assessment, analysis and management of occupational safety risks have become a relevant problem, and given its complexity and multidimensionality, its solution is in high demand. Several publications have been devoted to the issues of risk assessment in the field of occupational health and safety (Ramos et al., 2020; Rosa et al., 2015; Tchiehe \& Gauthier, 2017; Silva et al., 2019; Nordlöf et al., 2017; Kim et al., 2019; Bianchini et al., 2017; Barb \& Fita, 2019; Darabont et al., 2017; Saracino et al., 2016). An analysis of scientific papers showed the lack a sound mathematical apparatus, expert decisions, and a single approach to hazard assessment. Regression models used for a mathematical analysis are ineffective, and scientific approaches are organisational in nature.

Zavadskas and Turskis used the multicriteria ARAS method to assess the microclimate in an office building. The ARAS method is based on quantitative measurements and the theory of practicality. In this method, the value of the auxiliary function determines the relative effectiveness of the alternative compared to other alternatives. This auxiliary function is directly proportional to the relative result of the criteria values and the weight significance of the criterion in question. The usefulness of using an alternative is determined by comparing the option with the ideally best alternative.

Ginevičius et al. (2015) studied features pertaining to the assessment of quality management systems. The researchers developed a set of dependencies between individual indicators of the process quality and their values on a dimensionless scale. This combination allowed a quantitative assessment of the quality of processes and permitted to consider the diversity of indicators and the significance of processes.

Trisch et al. (2016) proposed to assess the quality management system at the operational stage by assessing a set of interrelated processes, that is, to combine assessments of various processes in one data set and to assess it as a whole. According to researchers, the procedure increases the amount of information about the 
assessment of the quality of the system as a set of processes, which allows evaluating the entire system with greater objectivity and reliability. Aiming to solve this problem, the authors proposed statistical methods with non-parametric statistics, since non-parametric statistical data do not require to know the law of distribution of random values, but more statistical data that can be provided by combining assessments of quality processes.

Ginevičius and Podvezko $(2007,2008)$ used multicriteria methods for quantitative assessment of the quality of processes, which allow bringing their indicators to one dimension. The authors confirmed the SAW (simple additive weighing) method as the simplest and most widely applicable. This method aims to determine individual quality indicators and the values of their weights and then determine the integral value.

The multicriteria TOPSIS assessment method is a technique for order of preference by similarity to ideal solution (Ginevičius \& Podviezko, 2013; Ginevičius et al., 2014). The main idea of the method is to separately assess the remoteness of indicators from the initially determined ideal and anti-ideal points, and then to convert these two indicators into one general assessment (Šimelytė \& Antanavičienè, 2013; Beinoraitė \& Drejeris, 2014).

Different authors (Krivka, 2014; Brauers et al., 2014; Hashemkhani et al., 2015) used such multicriteria methods as PROMETHEE (preference ranking organisation method for enrichment evaluation), MOORA (multi-objective optimisation method by ratio analysis), WASPAS (weighted aggregated sum product assessment) to assess various social objects, including processes in organisations.

The analysed assessment methods have been used to assess the quality of products and various processes of the quality management system. Therefore, the literature review confirmed the relevance of the study aimed at developing methods for assessing the safety of working conditions in the workplace.

\section{RESEARCH METHODS}

The definition of the overall index of harmful factors in the workplace is associated with obtaining a single assessment that quantitatively expresses safety through its individual indicators. The following must be done to find it:

- to establish the characteristics to be assessed;

- to determine the frequency of monitoring and measurement of indicators of harmful factors;
- to determine the maximum and minimum acceptable value of each harmful factor indicator;

- to define the optimal value of each harmful factor indicator;

- depending on the optimal value of a single indicator, to determine the group, to which this indicator of harmful factors belongs:

- a group of indicators of harmful factors, in which the optimal (the best) value is directed to the lower limit of acceptable values, in accordance with regulatory requirements, e. g., vibration, noise etc. In this case, the less these indicators, the better;

- a group of indicators of harmful factors, in which the optimal (the best) value is directed towards the middle of the range of acceptable values, according to regulatory requirements, e. g., air temperature.

Considering that different groups of indicators of harmful factors have different optimal values, the authors of this article propose building dependencies for each group, which would allow unifying the system of dependencies to determine the assessment of any indicator. This type of dependency was first used by Dieringer (1980) for the optimisation of technological processes and by Gorbenko (2013) for the assessment of quality management systems. However, the authors of this article believe that their application in terms of determining the shape parameter is not perfect, which is the most important factor in the optimality of their application in practice. Below, this type of dependency is examined and applied to evaluate indicators of harmful factors.

The dependence is proposed to obtain an assessment of indicators of harmful factors on a dimensionless scale (from 0 to 1 ):

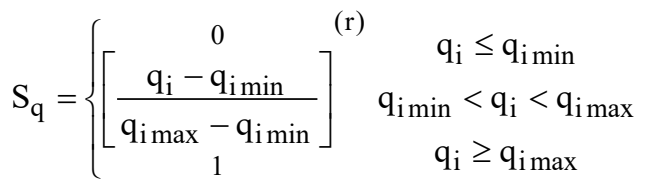

where $q_{i}$ - the actual value of the harmful factor indicator; $q_{\text {imin }}-$ minimum value of the harmful factor indicator; $q_{\text {imax }}-$ maximum value of the harmful factor indicator; $r$ - shape parameter that changes the shape of the dependency.

If the shape parameter $r$ is changed from 0.1 to unity in increments of 0.2 , then the dependencies will be curved upward, and if the shape parameter is changed from 1 to nine in increments of 2, then the dependence will be concave down (Fig. 1). 


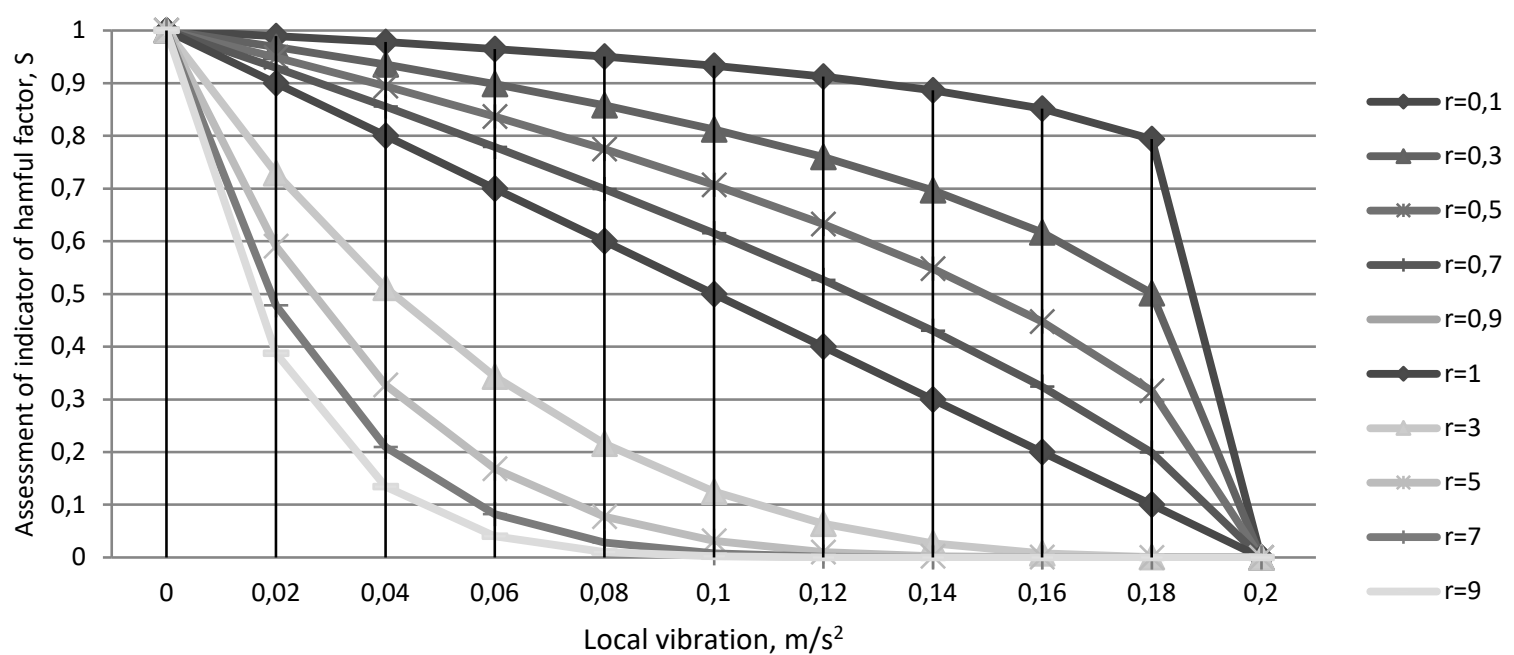

Fig. 1. Indicators of harmful factors, in which the optimal (the best) value is directed to the lower limit of the tolerance field, e. g., local vibration, no more than $0.2 \mathrm{~m} / \mathrm{s} 2$

If the optimal (the best) harmful factor indicator is the middle of the limit of acceptable values, then the dependence will look as follows:

$$
S_{q}= \begin{cases}{\left[\frac{q_{i}-q_{i \min }}{t_{i}-q_{i \min }}\right]^{(r)}} & q_{i \min } \leq q_{i} \leq t_{i} \\ {\left[\frac{q_{i}-q_{i \max }}{t_{i}-q_{i \max }}\right]^{(r)}} & t_{i}<q_{i} \leq q_{i \max } \\ q_{i \min }>q_{i}>q_{i \max }\end{cases}
$$

where $t_{i}-$ the middle of the limits of permissible values.

In this case, the dependency system will have the form shown in Fig. 2.

The result is a system of dependencies that allows obtaining assessments of indicators of harmful factors on a dimensionless scale. Next, the positive aspects of the dependency system should be considered. Firstly, these dependencies have a shape parameter that allows to change its shape and to choose the most suitable option for each indicator. Secondly, the proposed dependencies consider the maximum, minimum, and optimal value of the harmful factor indicator, as well as do not require manual adjustment of the rating scales. Thirdly, the simplicity of the models allows putting them into practice without special knowledge, which is particularly valuable when assessing the indicators of harmful factors in the workplace.

Aiming to transfer single different-sized indicators of harmful factors into a single dimensionless scale and to find a quantitative assessment, it is necessary to determine the dependence. The choice of one of ten dependencies is influenced by many factors,

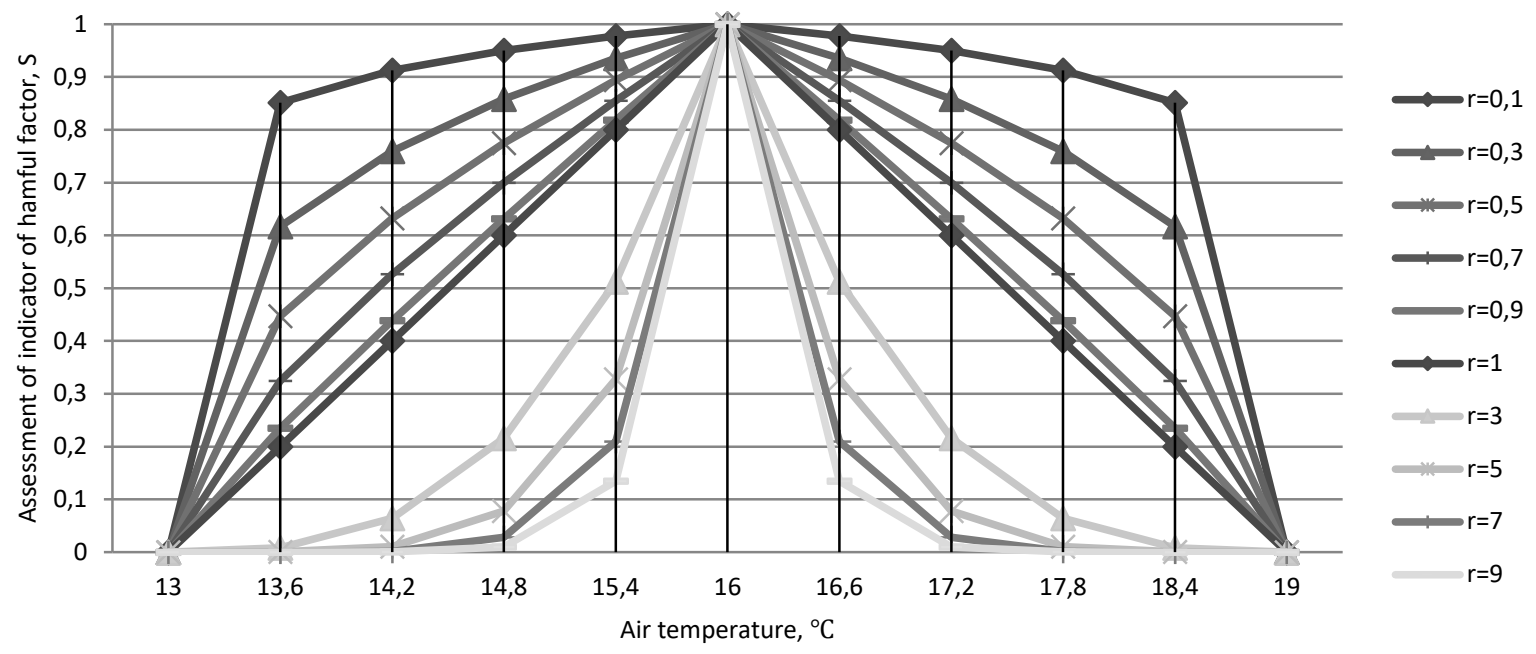

Fig. 2. Optimal (the best) harmful factor indicator goes to the middle of the range of acceptable values (air temperature) 
including the degree of influence on employee health, the complexity and specifics of the work, the period of the year etc. It is impossible to quantify this choice since each indicator has its characteristics and allowable regulatory requirements, which change over time. Therefore, it is necessary to turn to the theory of expert assessments, where decision-making is understood as the choice of an alternative from the set based on an analysis of factors or criteria.

The hierarchy analysis method (Saaty, 1980; Saaty, 2005) based on determining the weight of objects using paired comparisons is proposed for the selection of the necessary dependence for assessing a specific process. This method aims to present the problem in the form of a hierarchy, where the problem itself is on the first level (substantiation of the dependence choice) with the most important harmful factors from the experts' point of view placed on the second and the third hosting the parameters of the forms that should be assessed by characteristics of the second level. The criteria are compared in pairs regarding the impact on the final goal. The comparison uses the rating scale proposed by the author of the method. Based on the results of paired comparisons, a square matrix is constructed:

$$
\left(\begin{array}{cccc}
a_{11} & a_{12} & a_{13} & a_{1 n} \\
a_{21} & a_{22} & a_{23} & a_{2 n} \\
a_{31} & a_{32} & a_{33} & a_{3 n} \\
a_{n 1} & a_{n 2} & a_{n 3} & a_{n n}
\end{array}\right)
$$

Similar matrices are constructed for paired comparisons at the second level and with respect to the common goal at the first level and the third level with respect to the criteria of the second level. The general significance of the solution $\left(X_{i}=\frac{a_{j}}{S}\right.$, where $S$ is the sum of the assessment vectors) is found by obtaining the components of the eigenvector of the matrix as the geometric average of the row $\left(a_{j}=\sqrt[n]{a_{11} a_{12} a_{13} a_{1 n}}\right)$. A feature of this method is the built-in criterion for the quality of work performed by the experts - the consistency index.

One of the averages (arithmetic, geometric, harmonious) can be used to find the overall index of a harmful and dangerous factor, which makes it possible to bring together individual assessments. Determining the geometric mean value will give an assessment of occupational safety zero if one of the indicators is zero, and a unit, that is, the maximum value, can be obtained only when all unit indicators are equal to one. In this case, the overall harmful factor indicator is calculated by the formula:

$$
Q=\sqrt[n]{\prod_{i=1}^{n} S_{q i}}
$$

where $n-$ number of single harmful factor indicators; $S_{q i}-$ the value of the i single harmful factor indicators on a dimensionless scale.

The determination of the overall index can be carried out according to the formula of the harmonic mean:

$$
\frac{1}{Q}=\frac{1}{n} \sum_{i=1}^{n} \frac{1}{S_{q i}}
$$

Also, the overall harmful factor indicator can be defined as the arithmetic mean of assessments $S_{q i}$ :

$$
Q=\frac{1}{n} \sum_{i=1}^{n} S_{q i}
$$

Thus, the obtained value of the overall index of harmful factors provides grounds for decisions aimed at further improvement of the safety of working conditions.

\section{RESULTS AND DISCUSSION}

The studies were conducted at the machinebuilding plant to confirm the operability of the developed methodology for assessing the safety of working conditions. For assessment, harmful production factors in the foundry were examined. It was determined that microclimate (air temperature, relative humidity, air velocity, and thermal radiation intensity), noise and vibration were the main harmful production factors in the foundry.

The values of these indicators have been measured and recorded at workplaces and in the working area for 31 days. A combined device FLIR EM54 was used to measure air temperature, relative humidity, and air velocity. The intensity of thermal radiation was measured using a thermal meter "IK-metr". The noise level and general vibration were measured using a GM1351 digital sound level meter and an AR63A (GM63A) vibrometer. Permissible norms of harmful factors were determined in accordance with applicable regulatory documents.

Dependences (1), (2) were used to determine the assessments of indicators of harmful factors Sq on a dimensionless scale. To determine the shape parameter, according to the hierarchy analysis method, the following criteria were considered for paired comparisons: air temperature; relative humidity; air velocity; the intensity of thermal radiation; noise; and local vibration.

The selection of criteria and paired comparisons involved three experts, whose quality of work 
was verified using the consistency index. When comparing the consistency index with the average consistency, the consistency ratio for the 6th order matrix was $6 \%$, which corresponded to the condition $\leq 10 \%$.

The obtained experimental values of the above indicators of harmful factors and the results of mathematical transformations using the dependence are shown in Table 1.

The measurements were taken over a period of 31 days; therefore, Fig. 3 presents an example of a chart depicting the change in humidity depending on time.

Aiming to adjust the scales for each indicator of a harmful production factor, it is necessary to divide the difference between the minimum and maximum values by the number of intervals (ten such intervals in total), which is on the corresponding intermediate scale.

The graphic model for assessing indicators of harmful factors has the form presented in Fig. 4.

Since assessments of individual indicators of harmful factors have the same measurement scale $(0-1)$, the overall index can be found by applying one of the average values. In this case, the geometric mean value is applied.

$\mathrm{Q}=\sqrt[n]{\prod_{i=1}^{n} S_{q i}}=\sqrt[6]{0.96 \cdot 0.91 \cdot 0.62 \cdot 0.3 \cdot 0.5 \cdot 0.65}=0.61$

So, with the help of addition and experts, it is possible to find an overall index of the safety of working conditions in the workplace to determine the shape parameter. Thus, the application of the developed system of relationships between individual indicators of harmful production factors and their values on a dimensionless scale provides a quantitative assessment of the safety of working conditions in the workplace.

Based on the analysis of modern scientific research regarding the assessment of the safety of working conditions, the developed methodology establishes the basic principles and procedure for assessing safety and health at work using the developed system for dependencies of indicators of harmful factors with a dimensionless rating scale. The technique can be applied to all enterprises and organisations to assess harmful and dangerous factors in industrial premises.

Tab. 1. Results of the implementation of the methodology for assessing the safety of working conditions

\begin{tabular}{|c|c|c|c|c|c|c|c|}
\hline No. & Indicators of harmful factors & $\mathbf{q}_{\min }$ & $\mathbf{q}_{\max }$ & $\mathbf{q}_{\mathrm{opt}}$ & $q_{i}$ & $\mathbf{r}$ & $\mathbf{S}_{\mathrm{q}}$ \\
\hline 1 & air temperature, ${ }^{\circ} \mathrm{C}$ & 13 & 19 & 16 & 17 & 0.1 & 0.96 \\
\hline 2 & relative humidity, \% & 25 & 75 & 50 & 70 & 0.9 & 0.91 \\
\hline 3 & air velocity, $\mathrm{m} / \mathrm{s}$ & 0 & 0.5 & 0 & 0.1 & 0.3 & 0.62 \\
\hline 4 & intensity of thermal radiation, $\mathrm{W} / \mathrm{m}^{2}$ & 0 & 140 & 0 & 94 & 3 & 0.3 \\
\hline 5 & noise, dBA & 60 & 80 & 0 & 65 & 0.5 & 0.5 \\
\hline 6 & local vibration, $\mathrm{m} / \mathrm{s}^{2}$ & 0 & 0.2 & 0 & 0.09 & 0.7 & 0.65 \\
\hline
\end{tabular}

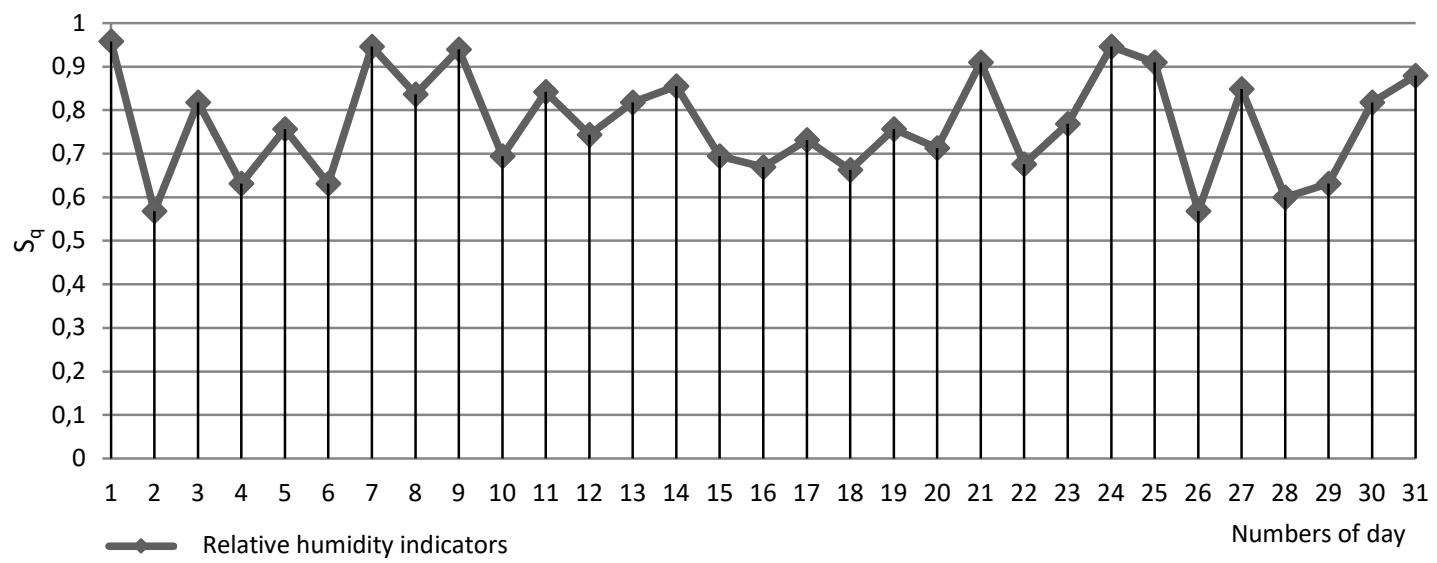

Fig. 3. Chart depicting the passage of time and the change in humidity indicators for 31 days 


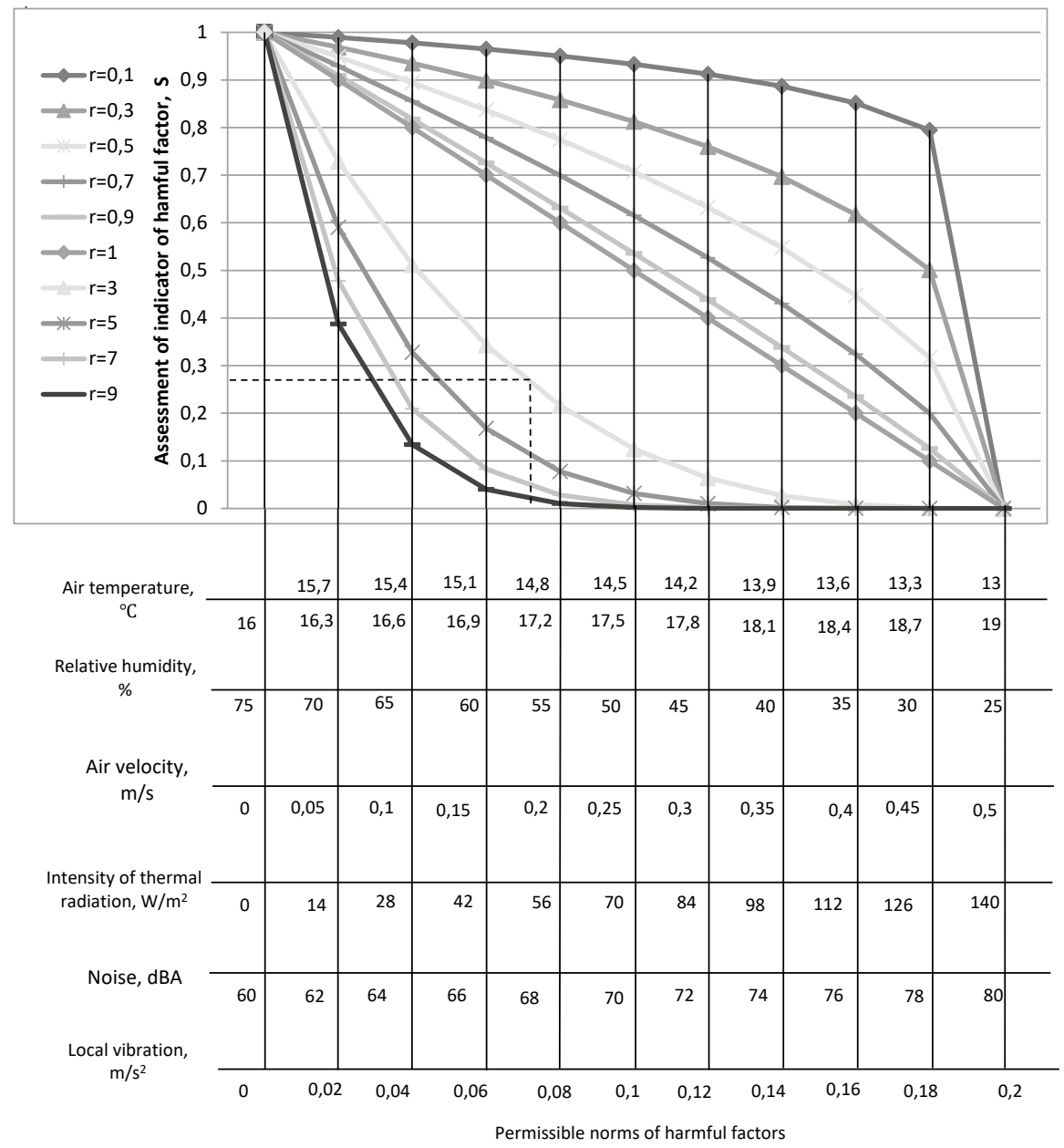

Fig. 4. Graphical model for assessing indicators of harmful factors

\section{CONCLUSIONS}

The article described the application of a system comprised of ten mathematical dependencies between single different-sized indicators of harmful factors and their assessments on a dimensionless scale from 0 to 1 , which made it possible to obtain a quantitative dimensionless assessment of the safety of working conditions in the workplace. A hierarchy analysis method was used to establish the shape parameter of mathematical dependencies based on a paired comparison of factors, to make a decision on determining safety and occupational health assessments from one of ten dependencies. The developed technique was tested at an enterprise. The results confirmed that this technique could be used for a quantitative assessment of the safety of working conditions in the workplace. The obtained results serve as grounds for improving the system of occupational safety management in the workplace.
Further research should consider the assessment of indicators of harmful factors over time and the determination of their numerical characteristics (variance, correlation), as well as examination of other possible dependencies that may result in a more reliable assessment.

\section{LITERATURE}

Azizi, M. H. (2010) Occupational Noise-induced Hearing Loss. International Journal of Occupational and Environmental Medicine, 3, 116-123.

Barb, C. M., \& Fita, D. N. (2019). A comparative analysis of risk assessment techniques from the risk management perspective. MATEC Web of Conferences, 290, 12003. doi: 10.1051/matecconf/201929012003

Beinoraitè, Š., \& Drejeris, R. (2014). Model for measuring the entrepreneurship of the population. Business: Theory and Practice, 15, 199-209. doi: 10.3846/ btp. 2014.20

Bianchini, A., Donini, F., Pellegrini, M., \& Saccani, C. (2017). An innovative methodology for measuring 
the effective implementation of an Occupational Health and Safety Management System in the European Union. Safety Science, 92, 26-33. doi: 10.1016/ j.ssci.2016.09.012

Bonner, J. C. (2010). Nanoparticles as a Potential Cause of Pleural and Interstitial Lung Disease. Proceedings of the American Thoracic Society, 7,138-141. doi: 10.1513/pats.200907-061RM

Brauers, W., Ginevičius, R., \& Podviezko, A. (2014). Development of a methodology of evaluation of financial stability of commercial banks. Panoeconomicus, 61, 349-367. doi: 10.2298/PAN1403349B

Darabont, D.-C., Bejinariu, C., Baciu, C., \& Bernevig-Sava, M.-A. (2017). Modern approaches in integrated management systems of quality, environmental and occupational health and safety. Quality - Acces to Succes, 20, 105-108.

Derringer, G., \& Suich, R. (1980). Simultaneous Optimization of Several Response Variables. Journal of Quality Technology, 12(4), 83-89.

Ginevičius, R., \& Podvezko, V. (2007). Complex assessment of sustainable development of state regions with emphasis on ecological and dwelling conditions. Ekologija, 53, 41-48.

Ginevičius, R., \& Podvezko, V. (2008). A feasibility study of multicriteria methods' application to quantitative evaluation of social phenomena. Business: Theory and Practice, 9, 81-87. doi: 10.3846/1648-0627.2008.9.81-87

Ginevičius, R., \& Podviezko, A. (2013). The evaluation of financial stability and soundness of Lithuanian Banks. Ekonomska istraživanja: znanstveno stručni časopis, 26, 191-208. doi: 10.1080/1331677X.2013.11517616

Ginevičius, R., Suhajda, K., \& Šimkūnaitè, J. (2014). Lithuanian experience of quantitative evaluation of socioeconomic system position by multicriteria methods. Procedia - Social and Behavioral Sciences, 110, 952 960. doi: 10.1016/j.sbspro.2013.12.941

Ginevičius, R., Trishch, H., \& Petraškevičius, V. (2015). Quantitative assessment of quality management systems processes. Economic Research Ekonomska Istraživanja, 28(1), 1096-1110. doi: 10.1080/133167 7X.2015.1087676

Gorbenko, N. (2013). Assessment of processes of enterprises quality management systems. Technology Audit And Production Reserves, 5(5(13)), 22-24. doi: $10.15587 / 2312-8372.2013 .18378$

Hashemkhani Zolfani, S., Maknoon, R., \& Zavadskas, E. K. (2015). Multiple Nash equilibriums and evaluation of strategies. New application of MCDM methods. Journal of Business Economics and Management, 16, 290-305. doi: 10.3846/16111699.2014.967715

Holubova, V. (2016). Integrated safety management systems. Polish Journal of Management Studies, 14(1), 106-118. doi: 10.17512/pjms.2016.14.1.10

Kim, N. K., Rahim, N. F. A., Iranmanesh, M., \& Foroughi, B. (2019). The role of the safety climate in the successful implementation of safety management systems. Safety Science, 118, 48-56. doi: 10.1016/j.ssci.2019.05.008

Krivka, A. (2014). Complex evaluation of the economic crisis impact on Lithuanian industries. Journal of Business Economics and Management, 15, 299-315. doi: $10.3846 / 16111699.2013 .867277$
Nordlöf, H., Wiitavaara, B., Högberg, H., \& Westerling, R. (2017). A cross-sectional study of factors influencing occupational health and safety management practices in companies. Safety Science, 95, 92-103. doi: 10.1016/j.ssci.2017.02.008

Ramos, D., Afonso, P., \& Rodrigues, M. A. (2020). Integrated management systems as a key facilitator of occupational health and safety risk management: A case study in a medium sized waste management firm. Journal of Cleaner Production, 262, 121346. doi: 10.1016/j.jclepro.2020.121346

Rosa, L. V., Haddad, A. N., \& Carvalho, de P. V. R. (2015). Assessing risk in sustainable construction using the Functional Resonance Analysis Method (FRAM). Cognition, Technology \& Work, 17(4), 559-573. doi: 10.1007/s10111-015-0337-z

Saaty, T. (1980). The analytic hierarchy process. New-York, United States: McGraw-Hill.

Saaty, T. L. (2005). The analytic hierarchy and analytic network processes for the measurement of intangible criteria and for decision-making. In J. Figueira, S. Greco, \& M. Ehrgott (Eds.), Multiple criteria decision analysis: State of the art survey (pp. 345-408). Springer.

Saracino, A., Moreno, V. C., Antonioni, G., Spadoni, G., \& Cozzani, V. (2016). Application of a self-assessment methodology for occupational safety to biogas industry. Chemical Engineering Transactions, 53, 247-252. doi: 10.3303/CET1653042

Silva, F., Arezes, P., \& Swuste, P. (2019). Risk management. Nanotechnology in Eco-Efficient Construction, 755784. doi:10.1016/b978-0-08-102641-0.00029-3

Šimelytè, A., \& Antanavičienè, J. (2013). The effect of investment promotion on FDI flows: A case of the Baltic States. Business: Theory and Practice, 14, 200-208. doi: 10.3846/btp.2013.21

Suuronen, K., Jolanki, R., Luukkonen, R., Alanko, K., \& Susitaival, P. (2007). Self-reported skin symptoms in metal workers. Contact Dermatitis, 57, 259-264. doi: 10.1111/j.1600-0536.2007.01207.x

Tabor, J. (2018). A grey-based decision-making approach to the improvement of OHS management system. Polish Journal of Management Studies, 18, 389-402. doi: 10.17512/pjms.2018.18.1.29

Tchiehe, D. N., \& Gauthier, F. (2017). Classification of risk acceptability and risk tolerability factors in occupational health and safety. Safety Science, 92, 138-147. doi: $10.1016 /$ j.ssci.2016.10.003

Trisch, R., Gorbenko, E., Dotsenko, N., Kim, N., \& Kiporenko, A. (2016). Development of qualimetric approaches to the processes of quality management system at enterprises according to international standards of the ISO 9000 series. Eastern-European Journal of Enterprise Technologies, 4/3(82), 18-24. doi: 10.15587/1729-4061.2016.75503

Zavadskas, E. K., \& Turskis, Z. (2010). A new additive ratio assessment (ARAS) method in multicriteria decision-making. Technological and Economic Development of Economy, 16(2), 159-172. doi: 10.3846/ tede. 2010.10 